\title{
Novel blends of acrylonitrile butadiene rubber and polyurethane-silica hybrid networks
}

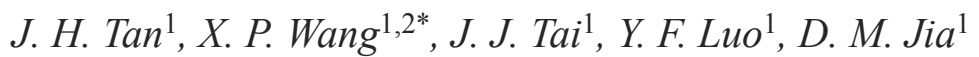 \\ ${ }^{1}$ School of Materials Science and Engineering, South China University of Technology, 510640 Guangzhou, China \\ ${ }^{2}$ State Key Laboratory of Subtropical Building Science, South China University of Technology, 510640 Guangzhou, \\ China
}

Received 23 November 2011; accepted in revised form 31 January 2012

\begin{abstract}
Novel blends of acrylonitrile butadiene rubber (NBR) and polyurethane-silica $\left(\mathrm{PU}-\mathrm{SiO}_{2}\right)$ hybrid networks have been prepared by melt blending. The $\mathrm{PU}-\mathrm{SiO}_{2}$ hybrid networks were formed via the reaction of NCO groups of NCO-terminated PU prepolymer and $\mathrm{OH}$ groups of $\mathrm{SiO}_{2}$ in the absence of an external crosslinking agent (i.e. alcohols and amines) during the curing process of NBR. Both in the neat $\mathrm{PU}-\mathrm{SiO}_{2}$ system and the NBR/(PU-SiO 2$)$ system, the NCO-terminated PU prepolymer could be crosslinked by $\mathrm{SiO}_{2}$ to form $\mathrm{PU}-\mathrm{SiO}_{2}$ hybrid networks. The effects of $\mathrm{PU}-\mathrm{SiO}_{2}$ introduction into the NBR, on the properties of the resulting blends were studied. It was found that the vulcanization was activated by the incorporation of $\mathrm{PU}-\mathrm{SiO}_{2}$. Transmission electronic microscopy (TEM) studies indicated that the interpenetration and entanglement structures between NBR and $\mathrm{PU}-\mathrm{SiO}_{2}$ increased with increasing $\mathrm{PU}-\mathrm{SiO}_{2}$ content and the quasi-interpenetrating polymer networks (quasi-IPN) structures were formed when the $\mathrm{PU}-\mathrm{SiO}_{2}$ was $50 \mathrm{wt} \%$ in the NBR/(PU-SiO 2$)$ systems. The microstructures formed in the blends led to good compatibility between NBR and $\mathrm{PU}-\mathrm{SiO}_{2}$ and significantly improved the mechanical properties, abrasion resistance and flex-fatigue life of the blends.
\end{abstract}

Keywords: polymer blends and alloys, acrylonitrile butadiene rubber, polyurethane, silica, hybrid materials

\section{Introduction}

Polymer blends have been of great interest particularly in the last two decades or so. The factors that have fueled this interest are cost and time associated with the development of new polymers and the ability to tailor properties by blending, which may result in new, desirable and, in some cases, unexpected synergistic effects on the properties $[1,2]$. Acrylonitrile butadiene rubber (NBR) possesses attractive properties, such as good oil resistance, abrasion resistance, elastic properties and low gas permeability, and is widely applied in a wide range of industrial equipment. However, the mechanical properties, ozone resistance and processibility of NBR are poor [3]. Fillers such as silica, carbon and clay are usually added to improve its mechanical strength [4-7]. However, the addition of fillers has some limitations and desired properties cannot be achieved. The blending of NBR with another polymer can overcome these limitations.

Polyurethane (PU) is applied in many different fields because of its excellent properties, including its high tensile modulus, abrasion resistance, tear resistance, chemical resistance, low-temperature elasticity as well as ease of processing $[8,9]$. The favorable properties of PU have raised interest in preparing NBR/PU blends, which can bring to NBR the valuable properties of PU, especially the high strength and excellent abrasion resistance. The applications of different forms of PU in NBR have been reported. Direct blending hydrothermal decomposed crosslinked PU (HD-PUR) or thermoplastic

\footnotetext{
${ }^{*}$ Corresponding author, e-mail: wangxp@scut.edu.cn (c) BME-PT
} 
PU (TPU) with NBR can obtain NBR/PU blends [10-12]. However, these blends generally exhibit poor mechanical properties because of incompatibility and phase separation of the initial components. In order to minimize phase separation and increase interfacial adhesion, compatilizers usually are used for these systems, but this would lead to the increased cost and entail the use of complicated procedures. Dynamically cured TPU and NBR blends were prepared by Tang et al. [13]. They reported that the mechanical properties for these NBR/TPU dynamically cured blends were much better than those for NBR/TPU simple blend systems. However, in the NBR/TPU blends, the TPU phase is linear structure, not a crosslinked network, which restricts further properties improvement of the blends. The blends of NBR and PU ionomers were prepared by Dimitrievski et al. [14]. They studied the influence of the PU ionomers on the blend properties, blend miscibility and on the course and kinetics of vulcanization. In addition, blends of NBR and in-situ produced PU have been studied. KargerKocsis et al. $[15,16]$ prepared rubber blends of hydrogenated nitrile rubber (HNBR) and PU, in which the crosslinked PU was formed from solid PU precursors, viz. polyol and blocked polyisocyanate, during curing of the HNBR rubber. The mechanical and tribological properties of the blends were researched. PU/NBR blends were prepared by Desai et al. [17] through a combination of solution blending and mastication process. However, the use of large quantity of organic solvents and complicated procedures limited the application of the method. In this work, novel blends of NBR and in-situ produced PU-silica ( $\mathrm{PU}-\mathrm{SiO}_{2}$ ) hybrid networks are prepared. The NCO-terminated PU prepolymer is firstly prepared, the silica $\left(\mathrm{SiO}_{2}\right)$ bearing numerous silanol groups is subsequently introduced, then the mixture of PU prepolymer and $\mathrm{SiO}_{2}$ is dispersed in NBR matrix during the mixing process. The PU$\mathrm{SiO}_{2}$ hybrid networks are formed via the reaction of $\mathrm{NCO}$ groups of NCO-terminated PU prepolymer and $\mathrm{OH}$ groups of $\mathrm{SiO}_{2}$ during the curing process of NBR. This process has not yet been reported in the literature. In this approach, the mixture of PU prepolymer and $\mathrm{SiO}_{2}$ is in a gel-like form, which is strongly favored in solid phase raw rubber compounding. It could be pointed out that the $\mathrm{SiO}_{2}$ in the mixture acts as not only as a reinforcing agent but also a crosslinking agent of the PU prepolymer. Compared with the traditional crosslinking agent $[18,19]$, such as trimethylopropane (TMP) and 4,4'-methylenebis-(2-chloroaniline) (MOCA), the crosslinking agent used in this work is economic and environmentally friendly.

The aim of this work was to prepare blends of NBR and in-situ produced $\mathrm{PU}-\mathrm{SiO}_{2}$ hybrid networks. The structures of the $\mathrm{PU}-\mathrm{SiO}_{2}$ hybrid materials and NBR/ $\left(\mathrm{PU}-\mathrm{SiO}_{2}\right)$ blends were characterized by Fouriertransform infrared (FTIR) spectroscopy, X-ray photoelectron spectroscopy (XPS), differential scanning calorimetry (DSC) and transmission electronic microscopy (TEM). The effects of $\mathrm{PU}-\mathrm{SiO}_{2}$ content on the vulcanization, compatibility, mechanical properties, abrasion resistance and flex-fatigue life of the blends were studied.

\section{Experimental}

\subsection{Materials}

Isophorone diisocyanate (IPDI) from Bayer (Germany) was purified by vacuum distillation. Poly (tetramethylene glycol) (PTMG, $M_{\mathrm{n}}=1000 \mathrm{~g} / \mathrm{mol}$ ) from Mitsui (Japan) and dibutyltin dilaurate (DBTDL, as catalyst) from Shanghai Reagent Co., (Shanghai, China) were dried at $80^{\circ} \mathrm{C}$ under vacuum (10mmHg) for $8 \mathrm{~h}$ before use. The NBR with acrylonitrile content $26 \%$ was kindly provided by Japan Synthetic Rubber Company. Tetramethyl thiuram disulfide (TMTD), 2,2'-dibenzothiazole disulfide (DM), zinc oxide ( $\mathrm{ZnO})$, stearic acid (SA) and sulfur (S) were obtained from Kemai Chemical Technical Co. Ltd. (Tianjin, China). Precipitated silica bearing surface silanol groups was purchased from Huiming Chemical Technical Co. Ltd. (Jiangxi, China). The surface area and primary particle size are $210 \mathrm{~m}^{2} / \mathrm{g}$ and $20 \mathrm{~nm}$ respectively.

\subsection{Preparation of the mixture of $P U$ prepolymer and $\mathrm{SiO}_{2}$}

Weighed amounts of PTMG and DBTDL (0.05 wt \% based on PUs) were charged into a round-bottomed flask, heated until $85^{\circ} \mathrm{C}$, and thoroughly mixed with a predetermined amount of IPDI, which corresponded to a fixed $\mathrm{NCO} / \mathrm{OH}$ ratio of 2:1. The reaction system was stirred vigorously with mechanical stirring, under a dry nitrogen atmosphere. The completion of the reaction was determined by the di-nbutylamine titration method when the theoretical 
NCO percentage was reached. Then, the NCO-terminated PU prepolymer was obtained. After the PU prepolymer had cooled to room temperature, calculated amounts of $\mathrm{SiO}_{2}$ (30 wt\% based on PU prepolymer) was added, and the mixture was stirred at room temperature until it turn into gel-like form (for about $10 \mathrm{~min}$ ), then the mixture of PU prepolymer and $\mathrm{SiO}_{2}$ was obtained.

\subsection{Preparation of blends of NBR and $\mathrm{PU}_{-\mathrm{SiO}_{2}}$ hybrid networks}

A two-roll mill (Kesheng Co. Ltd. Guangzhou, China) was used to prepare the NBR/(PU-SiO $\left.{ }_{2}\right)$ compounds. First, NBR and additives were mixed at room temperature for about $7 \mathrm{~min}$, and then the calculated amounts of mixture of PU prepolymer and $\mathrm{SiO}_{2}$ was added to the NBR compounds. The NBR compounds and mixture of PU prepolymer and $\mathrm{SiO}_{2}$ were mixed uniformly at room temperature for about $5 \mathrm{~min}$, then the $\mathrm{NBR} /\left(\mathrm{PU}-\mathrm{SiO}_{2}\right)$ compounds were vulcanized in a standard mold at $120^{\circ} \mathrm{C}$ for optimal cure time $\left(t_{90}\right)$, which was determined by the U-CAN UR-2030 vulcameter (Taiwan, China). During the curing of the NBR/(PU-SiO $\left.{ }_{2}\right)$ compounds, the NCO groups of $\mathrm{PU}$ prepolymer reacted with $\mathrm{OH}$ groups of $\mathrm{SiO}_{2}$ and the $\mathrm{PU}-\mathrm{SiO}_{2}$ hybrid networks were produced, and the linear molecular chains of NBR were crosslinked into three-dimensional networks under the action of the vulcanization system. Therefore, the blends based on NBR and $\mathrm{PU}-\mathrm{SiO}_{2}$ hybrid networks were generated. Figure 1 shows the schematic reaction of PU prepolymer and $\mathrm{SiO}_{2}$. In the present study, the recipe for NBR system was as follows (phr): NBR 100; ZnO 5; stearic acid 1.5, sulfur 1.5; TMTD 0.3; DM 1.5. The weight content of mixture of PU prepolymer and $\mathrm{SiO}_{2}$ were $10,20,30,40$ and $50 \%$ in the NBR/(PU$\left.\mathrm{SiO}_{2}\right)$ blends, which were regarded as NBR/(PU-
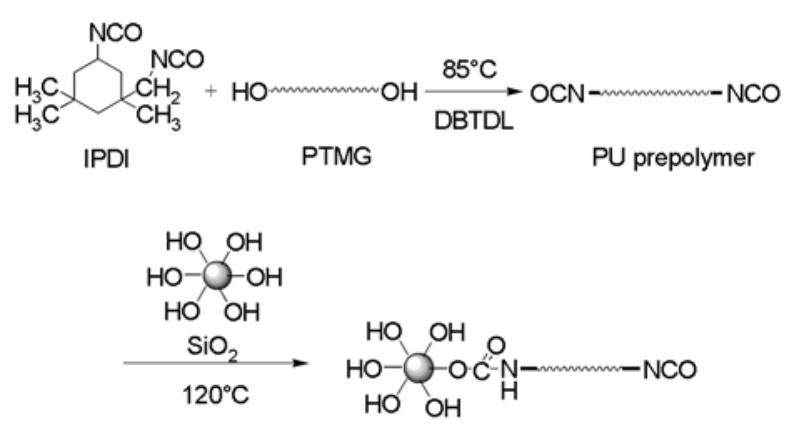

Figure 1. The schematic reaction of PU prepolymer and $\mathrm{SiO}_{2}$
$\left.\mathrm{SiO}_{2}\right)-10, \mathrm{NBR} /\left(\mathrm{PU}-\mathrm{SiO}_{2}\right)-20, \mathrm{NBR} /\left(\mathrm{PU}-\mathrm{SiO}_{2}\right)-30$, $\mathrm{NBR} /\left(\mathrm{PU}-\mathrm{SiO}_{2}\right)-40$ and NBR/(PU-SiO $\left.{ }_{2}\right)-50$, respectively. For comparison purposes, neat NBR and PU$\mathrm{SiO}_{2}$ sheets were also produced at $120^{\circ} \mathrm{C}$ using appropriate respective optimum cure times. Specimens for the investigations were cut from the compression molded sheets of ca. $2 \mathrm{~mm}$ thickness.

\subsection{Characterization}

Fourier-transform infrared (FTIR) spectroscopy was conducted on a Nicolet Fourier-transform infrared spectrophotometer (Thermo Nicolet Corporation, Nicoletis 10, America) at a resolution of $4 \mathrm{~cm}^{-1}$. PU prepolymer and $\mathrm{SiO}_{2}$ were tested by transmission mode; $\mathrm{PU}-\mathrm{SiO}_{2}$ hybrid materials, NBR vulcanizate and NBR/(PU-SiO $\left.)_{2}\right)-50$ blend were tested by attenuated total reflection mode.

X-ray photoelectron spectroscopy (XPS, Kratos Axis Ultra DLD, England) was performed to reveal the reaction between $\mathrm{PU}$ prepolymer and $\mathrm{SiO}_{2}$. $\mathrm{SiO}_{2}, \mathrm{PU}-\mathrm{SiO}_{2}$ hybrid materials and NBR/(PU$\mathrm{SiO}_{2}$ )-50 blend were tested with a monochromated Aluminum K $\alpha$ source $(1486.6 \mathrm{eV})$. All XPS spectra were calibrated to its reference $\mathrm{C} 1 \mathrm{~s}$ component at $285.0 \mathrm{eV}$ [20]. The $\mathrm{PU}-\mathrm{SiO}_{2}$ hybrid materials and $\mathrm{NBR} /\left(\mathrm{PU}-\mathrm{SiO}_{2}\right)-50$ blend were treated with butanone extraction and dried at $80^{\circ} \mathrm{C}$ for XPS test. The unreacted NCO-terminated PU prepolymer and $\mathrm{SiO}_{2}$ should be removed by butanone extraction; otherwise they would interfere with the XPS results.

The isothermal curing process of the NBR, mixture of PU prepolymer and $\mathrm{SiO}_{2}$ and $\mathrm{NBR} /\left(\mathrm{PU}-\mathrm{SiO}_{2}\right)-50$ compound were assessed by differential scanning calorimetry (DSC). The measurements were performed on a TA Q20 (New Castle, America) under $\mathrm{N}_{2}$ atmosphere. The aluminum pans containing the samples were inserted onto the DSC sensor at $120^{\circ} \mathrm{C}$ and left at $120^{\circ} \mathrm{C}$ for $200 \mathrm{~min}$.

Vulcanization parameters and curing curve for NBR, $\mathrm{PU}-\mathrm{SiO}_{2}$ and NBR/PU-SiO ${ }_{2}$ compounds were tested in an oscillating disk rheometer (ODR) according to ASTM D2084 using a U-CAN UR2030 vulcameter. The temperature was set at $120^{\circ} \mathrm{C}$, with a rotation amplitude of $1^{\circ}$. The compounds were tested under pressure in the die cavity located in the electrically heated plates. The cavity was formed by a fixed lower die and a movable upper die. The ODR maintained a contact with the specimen until the cure reaction was completed. 
The specimens were ultramicrotommed into thin pieces of about $120 \mathrm{~nm}$ thickness with a Leica EM UC6 (Wetzlar, Germany). Then the TEM observations were carried out using a Philips Tecnai 12 TEM (Amsterdam, Netherlands) at an accelerating voltage of $30 \mathrm{kV}$.

Dynamic Mechanical Analysis (DMA) spectra of the samples were obtained by using EPLEXOR @ $500 \mathrm{~N} / 1500 \mathrm{~N}$ advanced dynamic mechanical spectrometer (GABO Company, Germany). The specimens were analyzed in tensile mode at a constant frequency of $10 \mathrm{~Hz}$ and a strain of $0.5 \%$, and scanned from -100 to $100^{\circ} \mathrm{C}$ at a heating rate of $3^{\circ} \mathrm{C} / \mathrm{min}$.

The tensile and tear tests of the vulcanizates were performed according to ASTM D412 and ASTM D624 specifications, respectively. U-CAN UT-2060 (Taipei, Taiwan) instrument was used with the crosshead speed of $500 \mathrm{~mm} / \mathrm{min}$. Shore A hardness was performed following ASTM D2240 using Sanling XY-1 sclerometer (Shanghai, China).

Akron abrasion loss was evaluated by a Gotech GT7012-A testing machine (Taipei, China) according to BS 903/A9. The flex-fatigue life was measured using a De Mattia GT-7011-D flexing machine (Taipei, China) according to ASTM D430. For each sample, three pieces were tested and the average flex-fatigue-life value was reported. The flex-fatigue life was defined by the cycles at which a visible crack, that is, a grade-one crack, appeared.

\section{Results and discussion}

\subsection{Structure characterization of $\mathrm{PU}-\mathrm{SiO}_{2}$ hybrid materials and $\mathrm{NBR} /\left(\mathrm{PU}-\mathrm{SiO}_{2}\right)$ blend}

\subsubsection{Fourier-transform infrared spectroscopy analysis}

The FTIR spectra of the NCO-terminated PU prepolymer, $\mathrm{SiO}_{2}, \mathrm{PU}-\mathrm{SiO}_{2}$ hybrid materials, NBR vulcanizate and $\mathrm{NBR} /\left(\mathrm{PU}-\mathrm{SiO}_{2}\right)-50$ blend are shown in Figure 2. The spectrum of the NCO-terminated PU prepolymer shows absorption peak at $2266 \mathrm{~cm}^{-1}$ corresponding to the NCO group. The characteristic peaks of urethane group are observed at 3326 and $1714 \mathrm{~cm}^{-1}$, corresponding to stretching vibrations of $\mathrm{N}-\mathrm{H}$ and $\mathrm{C}=\mathrm{O}$ groups, respectively. For the $\mathrm{SiO}_{2}$, the absorption peaks at 1094 and $800 \mathrm{~cm}^{-1}$ are associated with $\mathrm{Si}-\mathrm{O}-\mathrm{Si}$ asymmetrical and symmetrical stretching vibrations respectively, and the absorption peaks at 3446 and $960 \mathrm{~cm}^{-1}$ represent the

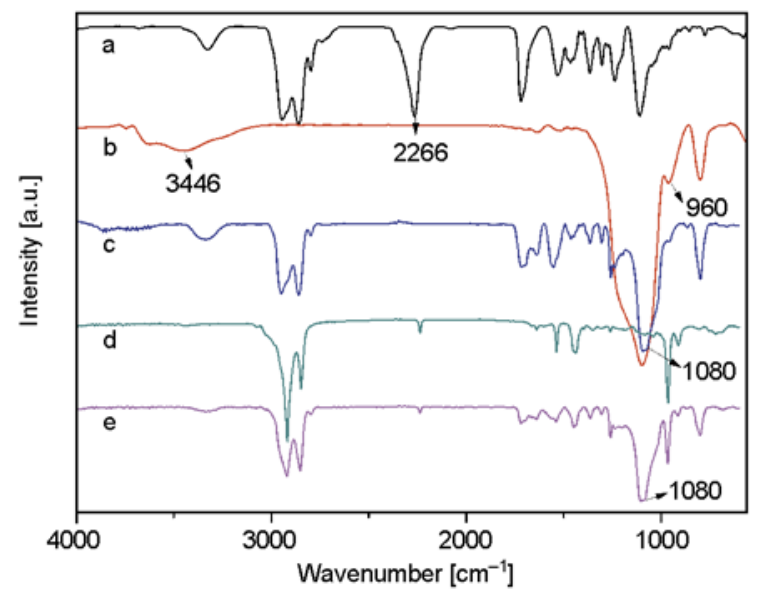

Figure 2. FTIR spectra of (a) NCO-terminated PU prepolymer, (b) $\mathrm{SiO}_{2}$, (c) $\mathrm{PU}-\mathrm{SiO}_{2}$ hybrid materials, (d) NBR vulcanizate and (e) NBR/(PU-SiO 2$)-50$ blend

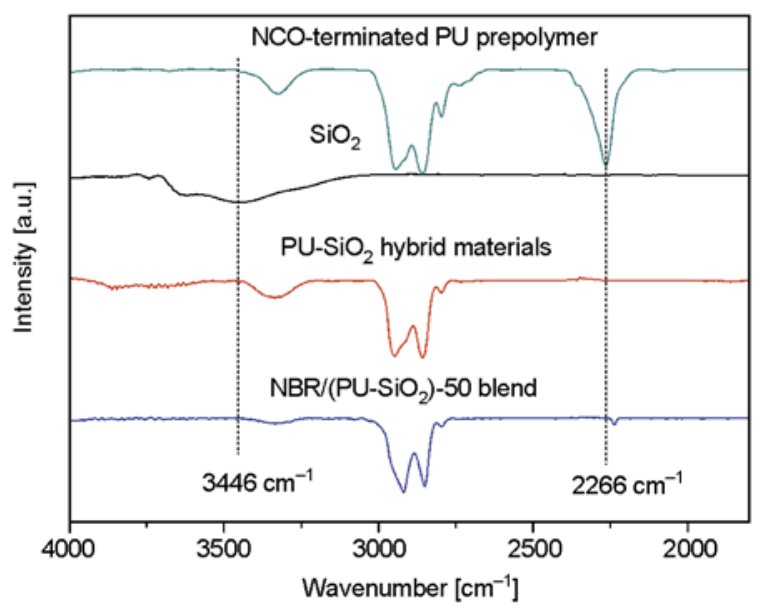

Figure 3. FTIR spectra of the NCO-terminated PU prepolymer, $\mathrm{SiO}_{2}, \mathrm{PU}-\mathrm{SiO}_{2}$ hybrid materials and NBR/ (PU-SiO $\left.{ }_{2}\right)-50$ blend in the region of 1800$4000 \mathrm{~cm}^{-1}$

$\mathrm{Si}-\mathrm{OH}$ stretching vibrations. The spectrum of NBR vulcanizate shows absorption peak at $2236 \mathrm{~cm}^{-1}$ corresponding to the $-\mathrm{CN}$ group. The $-\mathrm{CH}_{2}(2917$ and $\left.2847 \mathrm{~cm}^{-1}\right)$, the trans $>\mathrm{C}=\mathrm{CH}-\left(962 \mathrm{~cm}^{-1}\right)$ and the vinylidene $\left(>\mathrm{C}=\mathrm{CH}_{2} ; 910 \mathrm{~cm}^{-1}\right)$ are assigned to the NBR backbone. FTIR spectra of NCO-terminated $\mathrm{PU}$ prepolymer, $\mathrm{SiO}_{2}, \mathrm{PU}-\mathrm{SiO}_{2}$ hybrid materials and $\mathrm{NBR} /\left(\mathrm{PU}-\mathrm{SiO}_{2}\right)-50$ blend in the region of $1800-4000 \mathrm{~cm}^{-1}$ are reported in Figure 3. As shown in Figure 3, the absorption peaks of $\mathrm{NCO}$ at $2266 \mathrm{~cm}^{-1}$ and $\mathrm{Si}-\mathrm{OH}$ at $3446 \mathrm{~cm}^{-1}$ in $\mathrm{PU}-\mathrm{SiO}_{2}$ hybrid materials and NBR/(PU-SiO$\left.)_{2}\right)-50$ blend disappear. FTIR spectra of the $\mathrm{SiO}_{2}, \mathrm{PU}-\mathrm{SiO}_{2}$ hybrid materials and $\mathrm{NBR} /\left(\mathrm{PU}-\mathrm{SiO}_{2}\right)-50$ blend in the region of $600-1200 \mathrm{~cm}^{-1}$ are shown in Figure 4 and the integration results of $\mathrm{Si}-\mathrm{OH}\left(960 \mathrm{~cm}^{-1}\right)$ and $\mathrm{Si}-\mathrm{O}-\mathrm{Si}$ 


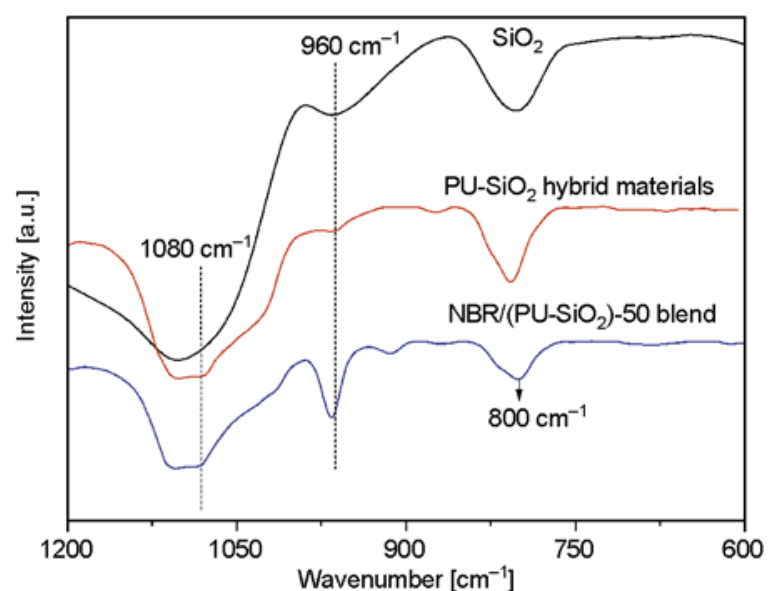

Figure 4. FTIR spectra of the $\mathrm{SiO}_{2}, \mathrm{PU}-\mathrm{SiO}_{2}$ hybrid materials and $\mathrm{NBR} /\left(\mathrm{PU}-\mathrm{SiO}_{2}\right)-50$ blend in the region of $600-1200 \mathrm{~cm}^{-1}$

Table 1. Integration results of $\mathrm{Si}-\mathrm{OH}$ and $\mathrm{Si}-\mathrm{O}-\mathrm{Si}$ in $\mathrm{SiO}_{2}$ and $\mathrm{PU}-\mathrm{SiO}_{2}$ hybrid materials

\begin{tabular}{|l|c|c|c|}
\hline & $\begin{array}{c}\mathbf{S i - O H} \\
\mathbf{( 9 6 0} \mathbf{~ c m}^{-\mathbf{1}} \mathbf{)}\end{array}$ & $\begin{array}{c}\mathbf{S i - O}-\mathbf{S i} \\
\left(\mathbf{8 0 0} \mathbf{~ c m}^{-\mathbf{1}} \mathbf{)}\right.\end{array}$ & $\mathbf{I}_{(\mathbf{S i}-\mathbf{O H})} \mathbf{/} \mathbf{I}_{(\mathbf{S i -}-\mathbf{O}-\mathbf{S i})}$ \\
\hline $\mathrm{SiO}_{2}$ & -3.24 & -9.40 & 0.35 \\
\hline $\mathrm{PU}_{-} \mathrm{SiO}_{2}$ & -0.48 & -7.47 & 0.06 \\
\hline
\end{tabular}

$\left(800 \mathrm{~cm}^{-1}\right)$ in $\mathrm{SiO}_{2}$ and $\mathrm{PU}-\mathrm{SiO}_{2}$ hybrid materials are reported in Table 1. For PU-SiO ${ }_{2}$ hybrid materials, the intensity ratio of $\mathrm{I}_{(960, \mathrm{Si}-\mathrm{OH})}$ to $\mathrm{I}_{(800, \mathrm{Si}-\mathrm{O}-\mathrm{Si})}$ is obviously decreased from $35 \%$ for $\mathrm{SiO}_{2}$ to $6 \%$ with a decrement about $29 \%$. The adsorption peak of $\mathrm{Si}-\mathrm{OH}$ bonds $\left(960 \mathrm{~cm}^{-1}\right)$ overlaps with the trans $>\mathrm{C}=\mathrm{CH}-$ bonds $\left(962 \mathrm{~cm}^{-1}\right)$ in NBR/(PU-SiO $)-50$ blend, while a weak absorption peak at $1080 \mathrm{~cm}^{-1}$

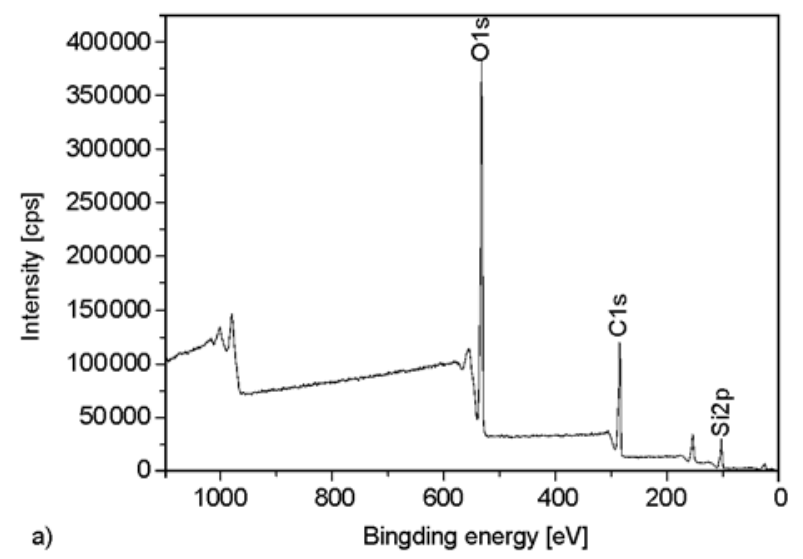

appears, corresponding to the $\mathrm{Si}-\mathrm{O}-\mathrm{C}$ bonds, and overlaps with $\mathrm{C}-\mathrm{O}-\mathrm{C}$ and $\mathrm{Si}-\mathrm{O}-\mathrm{Si}$ absorption peaks, which also appears in the $\mathrm{PU}-\mathrm{SiO}_{2}$ hybrid materials. All these changes indicate that the $\mathrm{NCO}$ groups of $\mathrm{PU}$ prepolymer have reacted with the $\mathrm{OH}$ groups of $\mathrm{SiO}_{2}$ in the neat $\mathrm{PU}-\mathrm{SiO}_{2}$ system and $\mathrm{NBR} /\left(\mathrm{PU}-\mathrm{SiO}_{2}\right)-50$ system.

\subsubsection{X-ray photoelectron spectroscopy analysis}

The low-resolution XPS spectra of the $\mathrm{SiO}_{2}$ and $\mathrm{PU}-\mathrm{SiO}_{2}$ hybrid materials are shown in Figure 5. As illustrated in Figure 5a, XPS survey spectrum of $\mathrm{SiO}_{2}$ shows the carbon peak at $285.1 \mathrm{eV}$, oxygen peak at $532.1 \mathrm{eV}$ and silicon peak at $103.3 \mathrm{eV}$ [21]. While in the Figure 5b, besides these peaks in $\mathrm{SiO}_{2}$, a new peak at $400.0 \mathrm{eV}$ appears, which is attributed to the nitrogen atom. Table 2 summarizes the characteristic XPS data. It can be seen that the ratios of $\mathrm{C} / \mathrm{Si}$ and $\mathrm{O} / \mathrm{Si}$ in $\mathrm{PU}-\mathrm{SiO}_{2}$ hybrid materials increase compared with those in $\mathrm{SiO}_{2}$. All the results can be explained by the fact that the PU prepolymer reacting with $\mathrm{SiO}_{2}$ introduces abundance carbon atoms, oxygen atoms and nitrogen atoms onto the surface of $\mathrm{SiO}_{2}$. The results demonstrate that the $\mathrm{NCO}$ groups of $\mathrm{PU}$ prepolymer have reacted with the $\mathrm{OH}$ groups of $\mathrm{SiO}_{2}$. The high-resolution XPS spectra of $\mathrm{Si} 2 \mathrm{p}$ in $\mathrm{SiO}_{2}, \mathrm{PU}-\mathrm{SiO}_{2}$ hybrid materials and NBR/(PU$\mathrm{SiO}_{2}$ )-50 blend are reported in Figure 6. It can be seen that the binding energy (BE) of $\mathrm{Si} 2 \mathrm{p} \mathrm{in} \mathrm{SiO}_{2}$ is located at $103.3 \mathrm{eV}$, while the $\mathrm{BE}$ shifts to a lower value in $\mathrm{PU}-\mathrm{SiO}_{2}$ hybrid materials and NBR/(PU-

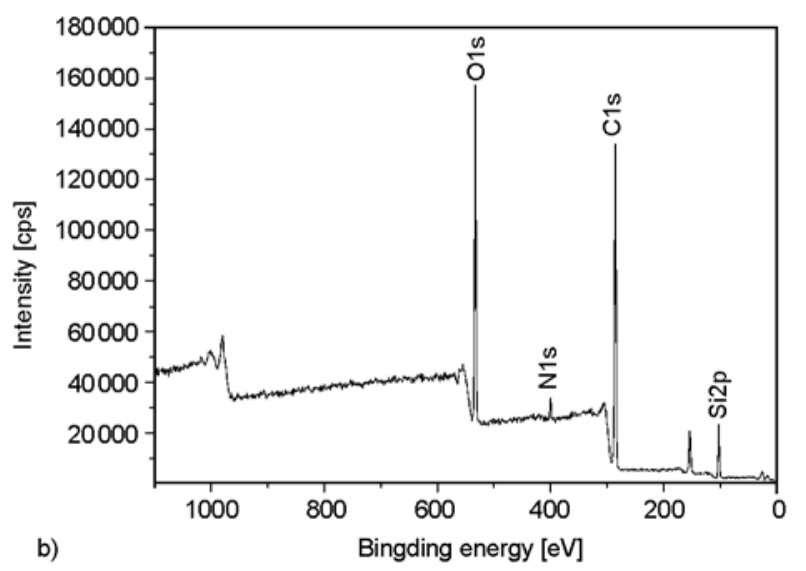

Figure 5. XPS spectra of (a) $\mathrm{SiO}_{2}$ and (b) $\mathrm{PU}-\mathrm{SiO}_{2}$ hybrid materials

Table 2. XPS atomic content for the $\mathrm{SiO}_{2}$ and $\mathrm{PU}-\mathrm{SiO}_{2}$ hybrid materials

\begin{tabular}{|c|c|c|c|c|c|c|}
\hline $\begin{array}{ll}\text { Samples } & \text { Atom } \\
\end{array}$ & $\begin{array}{c}\mathrm{C} \\
{[\%]}\end{array}$ & $\begin{array}{c}\mathbf{O} \\
{[\%]}\end{array}$ & $\begin{array}{c}\mathbf{S i} \\
{[\%]}\end{array}$ & $\begin{array}{c}\mathbf{N} \\
{[\%]}\end{array}$ & $\mathbf{C} / \mathbf{S i}$ & $\mathbf{O} / \mathbf{S i}$ \\
\hline $\mathrm{SiO}_{2}$ & 47.44 & 38.29 & 14.27 & 0 & 3.32 & 2.68 \\
\hline $\mathrm{PU}-\mathrm{SiO}_{2}$ hybrid materials & 64.99 & 25.70 & 7.01 & 2.30 & 9.27 & 3.67 \\
\hline
\end{tabular}




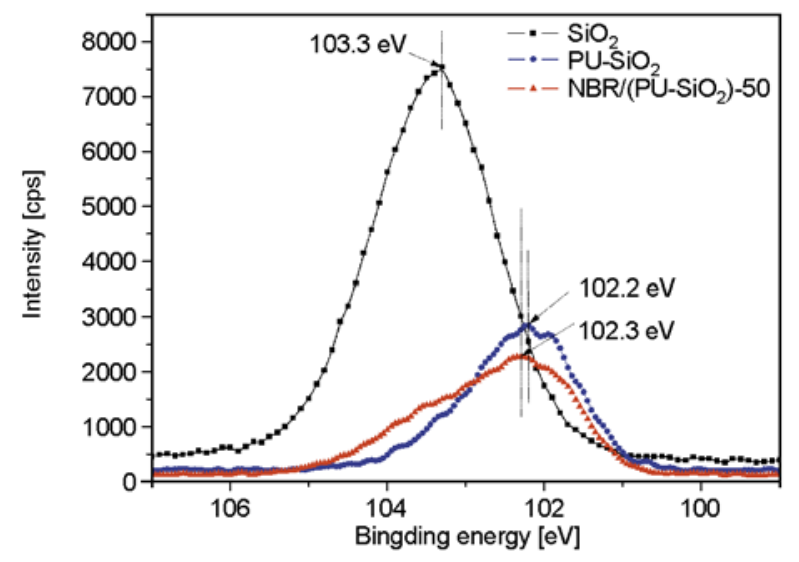

Figure 6. XPS spectra of $\mathrm{Si} 2 \mathrm{p}$ in $\mathrm{SiO}_{2}, \mathrm{PU}-\mathrm{SiO}_{2}$ hybrid materials and $\mathrm{NBR} /\left(\mathrm{PU}-\mathrm{SiO}_{2}\right)-50$ blend

$\mathrm{SiO}_{2}$ )-50 blend. This means that the chemical environments of $\mathrm{Si}$ atoms in $\mathrm{PU}-\mathrm{SiO}_{2}$ hybrid materials and $\mathrm{NBR} /\left(\mathrm{PU}-\mathrm{SiO}_{2}\right)-50$ blend have changed, which is mostly caused by the reaction of $\mathrm{NCO}$ groups of $\mathrm{PU}$ prepolymer and $\mathrm{OH}$ groups of $\mathrm{SiO}_{2}$.

\subsubsection{Differential scanning calorimetry analysis}

Figure 7 shows plots of the reaction heat as a function of time for NBR, mixture of $\mathrm{PU}$ prepolymer and $\mathrm{SiO}_{2}$ and $\mathrm{NBR} /\left(\mathrm{PU}-\mathrm{SiO}_{2}\right)-50$ compound during isothermal curing at $120^{\circ} \mathrm{C}$. As can be seen, DSC diagram of neat NBR exhibits an exothermic peak, which achieves a maximum at $76.1 \mathrm{~min}$. This exothermic peak is attributed to the crosslinking reaction of NBR molecular chains in the presence of curing agent. DSC trace of mixture of PU prepolymer and $\mathrm{SiO}_{2}$ shows an exothermic peak with a maximum at $6.5 \mathrm{~min}$. This exothermic peak is due to the reaction of $\mathrm{NCO}$ groups of PU prepolymer

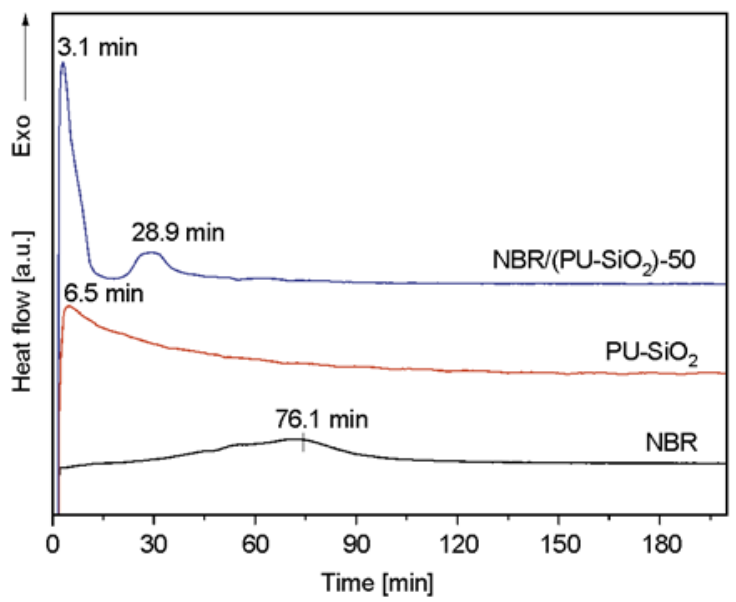

Figure 7. Curing time dependence of the heat flow during isothermal curing for NBR, mixture of PU prepolymer and $\mathrm{SiO}_{2}$ and $\mathrm{NBR} /\left(\mathrm{PU}-\mathrm{SiO}_{2}\right)-50$ compound at curing temperatures of $120^{\circ} \mathrm{C}$ and $\mathrm{OH}$ groups of $\mathrm{SiO}_{2}$. As for the NBR/(PU-SiO $)_{2}$ 50 compound, two exothermic peaks are observed: the exothermic peak with a maximum at $3.1 \mathrm{~min}$ and the one with a maximum at $28.9 \mathrm{~min}$. The former is attributed to the reaction of NCO groups and $\mathrm{OH}$ groups and the latter to the crosslinking reaction of NBR. This indicates that in the NBR/(PU$\mathrm{SiO}_{2}$ )-50 compound, both the NBR system and PU$\mathrm{SiO}_{2}$ system are cured successfully. From Figure 7, it can be seen that both the reaction peak times of NBR system and $\mathrm{PU}-\mathrm{SiO}_{2}$ system in the NBR/(PU$\mathrm{SiO}_{2}$ )-50 compound are reduced compared with those in the initial components. As for the NBR system in the NBR/(PU-SiO $\left.{ }_{2}\right)-50$ compound, the reaction peak time is $28.9 \mathrm{~min}$, which shows a decrease of $62 \%$ compared with that of neat NBR. This is possibly caused by two aspects, on one hand, the organic zinc compounds (produced by $\mathrm{ZnO}$ with accelerating agent, i.e. DM and TMTD, during the vulcanization of NBR) and TMTD (containing tertiary amine groups) in the NBR system have catalytic action on the NCO/OH reaction of $\mathrm{PU}-\mathrm{SiO}_{2}$ system [19]; on the other hand, the urethane groups (containing secondary amine functionalities) which are produced by $\mathrm{NCO}$ groups with $\mathrm{OH}$ groups in the $\mathrm{PU}-\mathrm{SiO}_{2}$ system have an accelerating effect on the vulcanization of NBR. The secondary amine functionalities form complexes with accelerator compounds, which promote the crosslinking reaction of NBR. Similar accelerating effects have been reported by Karger-Kocsis and coworkers [10, 22, 23]. Because of the mutual cure accelerating effects of NBR system and $\mathrm{PU}-\mathrm{SiO}_{2}$ system, the reaction peak times of NBR system and $\mathrm{PU}-\mathrm{SiO}_{2}$ system in the NBR/(PU-SiO $\left.)_{2}\right)-50$ compound are reduced.

\subsubsection{Morphology}

Figure $8 \mathrm{a}$ and $8 \mathrm{~b}$ show the TEM images of NBR/ (PU-SiO 2$)-30$ blend and NBR/(PU-SiO $\left.{ }_{2}\right)-50$ blend, respectively. In the images, the gray and white phases represent NBR and PU, respectively, and the black aggregates dispersed within the PU are silica. As shown in Figure 8a, when the $\mathrm{PU}-\mathrm{SiO}_{2}$ weight content is $30 \%$ in the blend, a sea-island morphology is formed. The PU appears as the disperse phase and NBR presents as the continuous phase. The average dimension of the PU phase is $0.3 \sim 1.0 \mu \mathrm{m}$. As the $\mathrm{PU}-\mathrm{SiO}_{2}$ weight content increases to $50 \%$, the NBR and PU show co-continuous morphology. As can be 


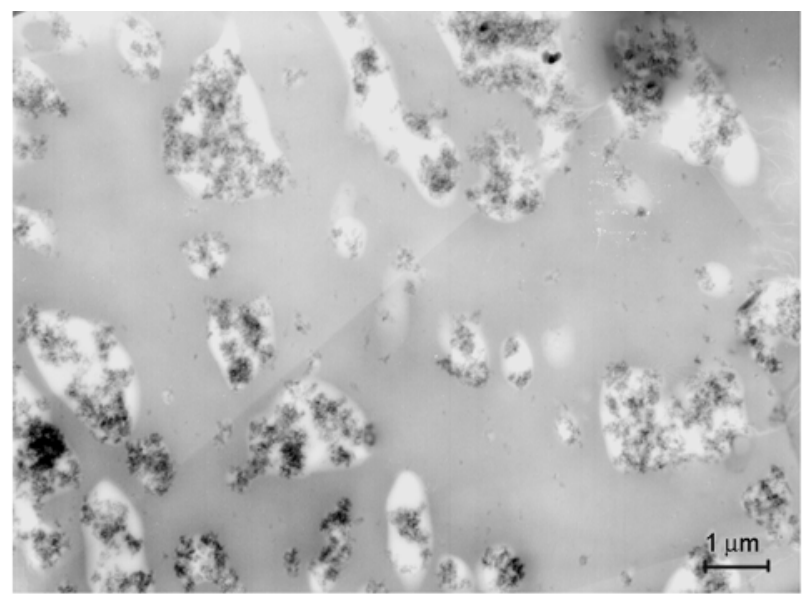

a)

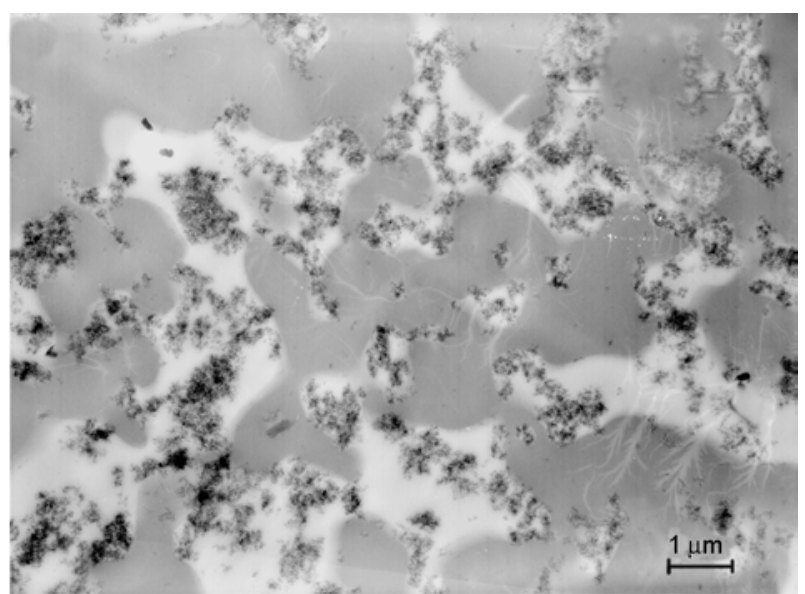

b)

Figure 8. TEM images of (a) NBR/(PU-SiO $\left.{ }_{2}\right)-30$ blend and (b) NBR/(PU-SiO 2$)-50$ blend

seen in Figure 8b, the structures formed in this blend are on the micrometer scale instead of the nanoscale (or molecular scale), which are more like quasi-interpenetrating polymer network (quasi-IPN). Similar results have been reported by Šebenik et al. [16]. The unique microstructures formed in the systems are beneficial to the improvement of compatibility between the two phases and enhancement of mechanical properties of NBR [16, 24], which will be illustrated below.

One may notice that the phase dimension in the blends is slightly large. This is because that the high molecular weight of the NBR leads to increased viscosity, which restrains the completely interpenetration between NBR and PU networks and the formation of fine structures. According to the method, silica is co-cured with PU and forms an independent network penetrated in the NBR network and there would be no chemical linkages between NBR and silica, therefore, the silica is restricted in the PU phase and no any discernible silica can be seen in the NBR phase. From the images it can be seen that some silica aggregates in the PU phase, which is mostly because that the high viscosity of PU prepolymer restrains the fine dispersion of silica in the process of blending.

\subsubsection{The formation of $\mathrm{NBR} /\left(\mathrm{PU}-\mathrm{SiO}_{2}\right)$ blends}

From the above structure analysis, we propose the formation process of NBR/(PU-SiO$\left.{ }_{2}\right)$ blends, as shown in Figure 9. First, the NBR gum and mixture of $\mathrm{PU}$ prepolymer and $\mathrm{SiO}_{2}$ are mixed by melt blending. Under the strong shear force of the blending process, the low molecular weight PU prepolymer and $\mathrm{SiO}_{2}$ can be easily mixed uniformly with NBR gum. In the process, the PU prepolymer molecular chains will interpenetrate with NBR molecular chains. Then the blends are cured at $120^{\circ} \mathrm{C}$. During

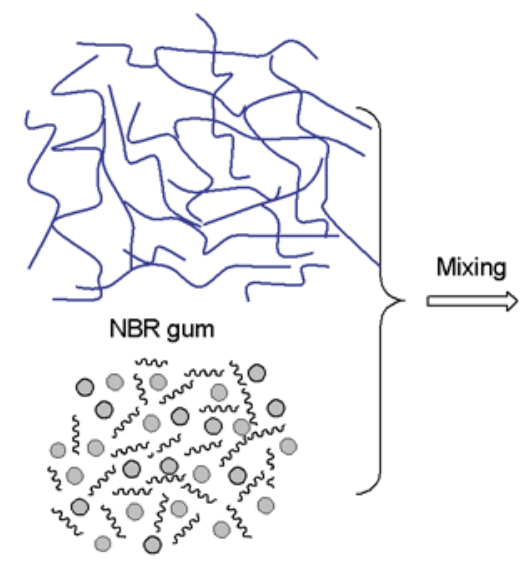

Mixture of $\mathrm{PU}$ prepolymer and $\mathrm{SiO}_{2}$

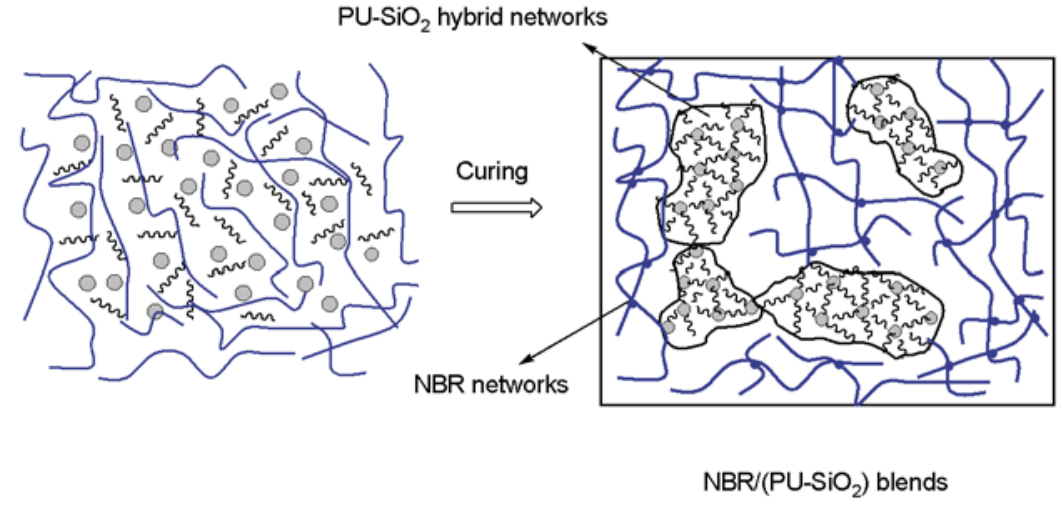

$\mathrm{OSiO}_{2}$

Figure 9. Schematic diagram for the formation process of $\mathrm{NBR} /\left(\mathrm{PU}-\mathrm{SiO}_{2}\right)$ blends 
the first 20 min of the curing process, the crosslinking reaction of $\mathrm{PU}-\mathrm{SiO}_{2}$ system plays a leading role. The NCO groups of PU prepolymer react with the $\mathrm{OH}$ groups of $\mathrm{SiO}_{2}$ to form $\mathrm{PU}-\mathrm{SiO}_{2}$ hybrid networks. About 20 min later, the crosslinking reaction of NBR is dominant. The linear NBR molecular chains are crosslinked into three-dimensional networks under the action of vulcanization system. Therefore, the blends based on NBR and $\mathrm{PU}-\mathrm{SiO}_{2}$ hybrid materials are generated. The interpenetrating structures between NBR and $\mathrm{PU}-\mathrm{SiO}_{2}$ in the blends achieved in the blending process are preserved by the curing process, which is important for the excellent properties of the resulting $\mathrm{NBR} /\left(\mathrm{PU}-\mathrm{SiO}_{2}\right)$ blends.

\subsection{Properties of $\mathrm{PU}-\mathrm{SiO}_{2}$ hybrid materials and $\mathrm{NBR} /\left(\mathrm{PU}-\mathrm{SiO}_{2}\right)$ blends}

\subsubsection{Curing characteristics}

The vulcanization curves of $\mathrm{NBR}, \mathrm{PU}-\mathrm{SiO}_{2}$ and $\mathrm{NBR} /\left(\mathrm{PU}-\mathrm{SiO}_{2}\right)$ compounds with different $\mathrm{PU}-\mathrm{SiO}_{2}$ loading are graphically represented in Figure 10. The vulcanization characteristics, expressed in terms of the vulcanization times, $t_{\mathrm{s} 2}$ (scorch time) and $t_{90}$

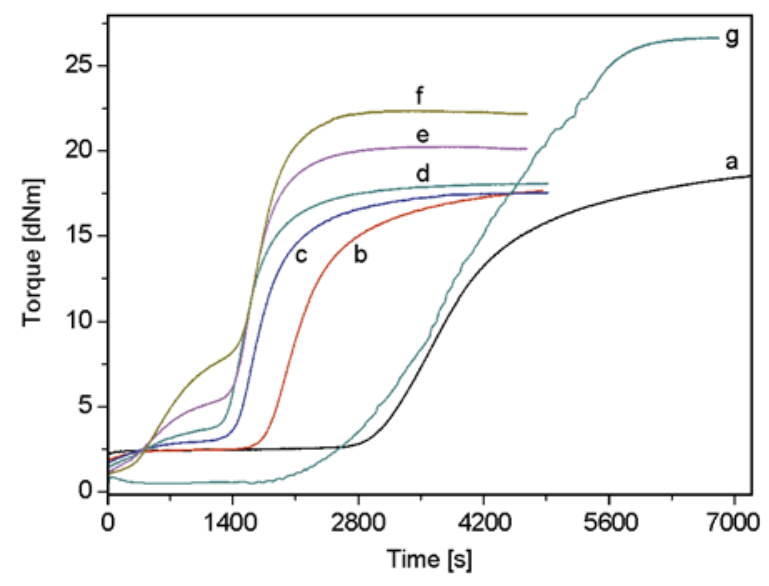

Figure 10. Vulcanization curves of (a) neat NBR, (b) NBR/(PU-SiO $)-10$, (c) NBR/(PU-SiO 2$)-20$, (d) NBR/(PU-SiO 2$)-30$, (e) NBR/(PU-SiO $\left.{ }_{2}\right)-40$, (f) $\mathrm{NBR} /\left(\mathrm{PU}-\mathrm{SiO}_{2}\right)-50$ and (g) $\mathrm{PU}-\mathrm{SiO}_{2}$ (optimum cure time), as well as the maximum and minimum values of the torque, $S_{\max }$ and $S_{\min }$, respectively, and delta torque $\Delta S\left(\Delta S=S_{\max }-S_{\min }\right)$, are deduced from the curves. These parameters, along with the cure rate index, $C R I$, expressed as $C R I=$ $\Delta S /\left(t_{90}-t_{\mathrm{s} 2}\right)$, which indicates the rate of cure of the compounds, are compiled in Table 3 . A higher value of CRI means a higher rate of vulcanization.

It was found that, compared with those of NBR and PU-SiO 2 , the $t_{\mathrm{s} 2}$ and $t_{90}$ of NBR/(PU-SiO $\left.)_{2}\right)$ compounds with different $\mathrm{PU}-\mathrm{SiO}_{2}$ loading are sharply reduced with the addition of $\mathrm{PU}-\mathrm{SiO}_{2}$. The NBR/ $\left(\mathrm{PU}-\mathrm{SiO}_{2}\right.$ ) compound with $50 \mathrm{wt} \% \mathrm{PU}-\mathrm{SiO}_{2}$ has $t_{\mathrm{s} 2}$ and $t_{90}$ of 8.22 and $34.93 \mathrm{~min}$, respectively, which show decreases of 84.3 and $62.1 \%$ compared with those of neat NBR. The cure rate index values of the NBR/(PU-SiO 2$)$ compounds, show an increase with addition of $\mathrm{PU}-\mathrm{SiO}_{2}$ and exceed those of the $\mathrm{NBR}$ and $\mathrm{PU}-\mathrm{SiO}_{2}$. The decreases in the scorch time and cure time accompanied with the increase in $C R I$ of $\mathrm{NBR} /\left(\mathrm{PU}-\mathrm{SiO}_{2}\right)$ compounds indicate that NBR system and $\mathrm{PU}-\mathrm{SiO}_{2}$ system tend to have an accelerating effect on the cure. These results are consistent with the conclusions derived from the reduced reaction peak times for the NBR system and PU$\mathrm{SiO}_{2}$ system in the NBR/(PU-SiO 2$)-50$ compound. The minimum torque shows a decrease with increasing $\mathrm{PU}-\mathrm{SiO}_{2}$ content for all NBR/(PU-SiO $\left.{ }_{2}\right)$ compounds. This indicates that the processability of the compounds is improved after the incorporation of $\mathrm{PU}-\mathrm{SiO}_{2}$. The increasing maximum torque indicates higher modulus as a result of the $\mathrm{PU}-\mathrm{SiO}_{2}$ addition. This is further supported by the increase in the difference between the maximum and minimum torque, $\Delta S$, upon $\mathrm{PU}-\mathrm{SiO}_{2}$ loading. As a consequence, $\mathrm{PU}-\mathrm{SiO}_{2}$ acts as a processing aid (improving the rheological properties of NBR) besides having an accelerating effect on the NBR vulcanization process. Note that, with increasing $\mathrm{PU}-\mathrm{SiO}_{2}$ content, especially when the $\mathrm{PU}-\mathrm{SiO}_{2}$ content achieves

Table 3. Vulcanization characteristics of NBR, $\mathrm{PU}-\mathrm{SiO}_{2}$ and NBR/(PU-SiO 2$)$ compounds with different $\mathrm{PU}_{-} \mathrm{SiO}_{2}$ loading

\begin{tabular}{|c|c|c|c|c|c|c|}
\hline $\begin{array}{c}\mathbf{P U}_{-S i \mathbf{O}_{2} \text { content }} \\
{[\mathbf{w t} \mathbf{0}]}\end{array}$ & $\begin{array}{c}\mathbf{t}_{\mathbf{s} 2} \\
{[\mathbf{m i n}]}\end{array}$ & $\begin{array}{c}\mathbf{t}_{\mathbf{9}} \\
{[\mathbf{m i n}]}\end{array}$ & $\begin{array}{c}\mathbf{S}_{\min } \\
{[\mathbf{d N m}]}\end{array}$ & $\begin{array}{c}\mathbf{S}_{\mathbf{m a x}} \\
{[\mathbf{d N m}]}\end{array}$ & $\begin{array}{c}\Delta \mathbf{S} \\
{[\mathbf{d N m}]}\end{array}$ & $\begin{array}{c}\mathbf{C I R} \\
{[\mathbf{d N m} / \mathbf{m i n}]}\end{array}$ \\
\hline $0(\mathrm{NBR})$ & 52.37 & 92.23 & 2.2 & 18.6 & 16.4 & 0.41 \\
\hline 10 & 30.25 & 53.93 & 1.9 & 17.4 & 15.5 & 0.65 \\
\hline 20 & 23.63 & 40.55 & 1.8 & 17.7 & 15.9 & 0.94 \\
\hline 30 & 15.35 & 36.48 & 1.5 & 18.1 & 16.6 & 0.79 \\
\hline 40 & 8.58 & 34.52 & 1.2 & 20.3 & 19.1 & 0.74 \\
\hline 50 & 8.22 & 34.93 & 1.1 & 22.4 & 21.3 & 0.80 \\
\hline $100\left(\mathrm{PU}_{-} \mathrm{SiO}_{2}\right)$ & 49.42 & 110.93 & 0.3 & 25.7 & 25.4 & 0.41 \\
\hline
\end{tabular}


$50 \mathrm{wt} \%$ (Figure 10f), the vulcanization curves of $\mathrm{NBR} /\left(\mathrm{PU}-\mathrm{SiO}_{2}\right)$ compounds appear to indicate two stages of cure acceleration. As can be seen from Figure 10f, one vulcanization accelerating stage begins at about $380 \mathrm{~s}$, and the other begins at about $1490 \mathrm{~s}$ for the NBR/(PU-SiO $\left.{ }_{2}\right)-50$ compound. The former stage is attributed to the crosslinking of PU$\mathrm{SiO}_{2}$ and the latter to the crosslinking of NBR, which is consistent with the two exothermic peaks of NBR/(PU-SiO $\left.{ }_{2}\right)-50$ compound during the isothermal curing at $120^{\circ} \mathrm{C}$. However, a possible mechanism for explaining this phenomenon is still under investigation.

\subsubsection{Dynamic mechanical analysis}

The DMA curves and data for the NBR, $\mathrm{PU}-\mathrm{SiO}_{2}$ and $\mathrm{NBR} /\left(\mathrm{PU}-\mathrm{SiO}_{2}\right)$ blends with different $\mathrm{PU}-\mathrm{SiO}_{2}$ loading are reported in Figure 11 and Table 4, respectively. From Figure 11 and Table 4, it can be seen that the $\tan \delta$ of the neat NBR exhibits one peak at $-17.8^{\circ} \mathrm{C}$, which corresponds to the $T_{\mathrm{g}}$, whereas PU has a $T_{\mathrm{g}}$ around $-23.6^{\circ} \mathrm{C}$ when we consider the position of the related $\tan \delta$ peaks. As for all the $\mathrm{NBR} /\left(\mathrm{PU}-\mathrm{SiO}_{2}\right)$ blends, the $T_{\mathrm{g}}$ around $-20^{\circ} \mathrm{C}$ is assigned to NBR, however the glass transition of $\mathrm{PU}-\mathrm{SiO}_{2}$ is not obvious. With the increasing of PU$\mathrm{SiO}_{2}$ content in the blends, the $T_{\mathrm{g}}$ of NBR in the $\mathrm{NBR} /\left(\mathrm{PU}-\mathrm{SiO}_{2}\right)$ blends shifts to a lower temperature and locates between the $T_{\mathrm{g}} \mathrm{s}$ of neat NBR and $\mathrm{PU}-\mathrm{SiO}_{2}$. The result indicates that the compatibility

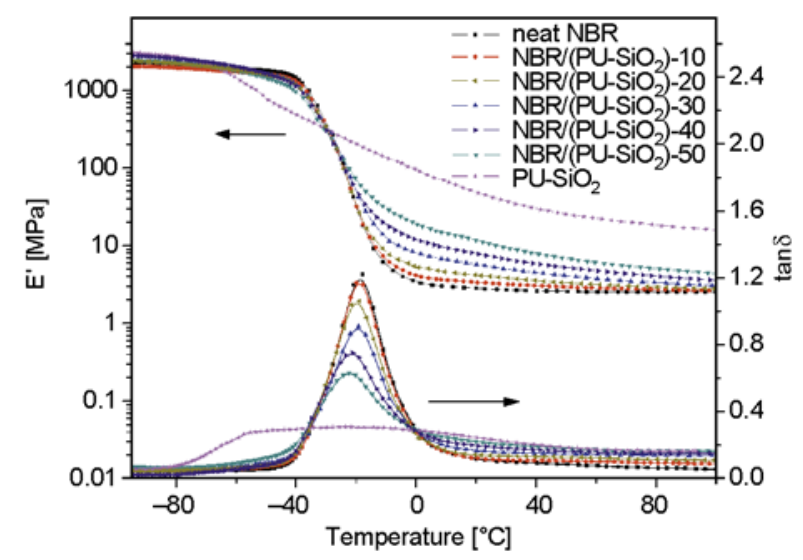

Figure 11. Storage modulus and $\tan \delta$ versus the temperature for $\mathrm{NBR}, \mathrm{PU}-\mathrm{SiO}_{2}$ and $\mathrm{NBR} /\left(\mathrm{PU}-\mathrm{SiO}_{2}\right)$ blends with different $\mathrm{PU}-\mathrm{SiO}_{2}$ loading between NBR phase and $\mathrm{PU}-\mathrm{SiO}_{2}$ phase is improved in the NBR/(PU-SiO 2$)$ blends $[25,26]$. From the above TEM analysis, we can see that with more PU$\mathrm{SiO}_{2}$ incorporated in NBR, the interpenetration and entanglement structures between NBR and $\mathrm{PU}-\mathrm{SiO}_{2}$ increase. The entanglement of the two polymers networks leads to forced 'compatibility' [27], which can not be achieved by usual blending method. As a result, the compatibility of $\mathrm{NBR}$ and $\mathrm{PU}-\mathrm{SiO}_{2}$ is improved with increasing $\mathrm{PU}-\mathrm{SiO}_{2}$ content. The broadening of the $\tan \delta$ peaks and decrease of $T_{\mathrm{g}}$ suggest that the damping properties and low temperature resistance of the blends are improved [28, 29]. With the addition of $\mathrm{PU}-\mathrm{SiO}_{2}$, a noticeable reduction in $\tan \delta$ peak height can be observed. The peak height of $\tan \delta$ curve decreases from 1.223 for NBR to 0.632 for NBR/(PU-SiO $\left.{ }_{2}\right)-50$ blend. The reduction in the $\tan \delta$ peak height can be correlated with the morphology of this blend. As discussed in TEM analysis, in NBR/(PU-SiO $\left.{ }_{2}\right)-50$ blend, the NBR and PU form a co-continuous morphology, which enhances interpenetration and entanglement of the two phases and restricts the motion of the polymers molecular chains. As a result, the $\tan \delta$ peak height reduces greatly.

From the DMA curves of the storage modulus $\left(E^{\prime}\right)$ versus temperature, it is evident that the more PU$\mathrm{SiO}_{2}$ is incorporated in the NBR, the higher the modulus in the rubbery plateau of the NBR is, which shows that the addition of $\mathrm{PU}-\mathrm{SiO}_{2}$ into NBR results in a remarkable increase of stiffness. This observation provides further evidence that the strong confinement of interpenetration network on the rubber chains. These results are in accordance with that the $S_{\max }$ increases with adding $\mathrm{PU}-\mathrm{SiO}_{2}$.

\subsubsection{Mechanical properties}

The stress-strain behaviors of NBR, $\mathrm{PU}-\mathrm{SiO}_{2}$ and $\mathrm{NBR} /\left(\mathrm{PU}-\mathrm{SiO}_{2}\right)$ blends with different $\mathrm{PU}-\mathrm{SiO}_{2}$ loading are presented in Figure 12 and Table 5. From the results it can be seen that NBR shows very poor mechanical properties. It is quite obvious because of the fact that NBR is a random copolymer having no regular structure. However, with the incorporation of the $\mathrm{PU}-\mathrm{SiO}_{2}$ in the NBR matrix, significant

Table 4. DMA data of NBR, $\mathrm{PU}-\mathrm{SiO}_{2}$ and NBR/(PU-SiO 2$)$ blends with different $\mathrm{PU}-\mathrm{SiO}_{2}$ loading

\begin{tabular}{|l|c|c|r|r|r|r|r|}
\hline $\mathbf{P U}_{-} \mathbf{S i O}_{2}$ content $[\mathbf{w t} \%]$ & $\mathbf{0}(\mathbf{N B R})$ & $\mathbf{1 0}$ & $\mathbf{2 0}$ & $\mathbf{3 0}$ & $\mathbf{4 0}$ & $\mathbf{5 0}$ & $\mathbf{1 0 0}_{\left(\mathbf{P U}-\mathbf{S i O}_{2}\right)}$ \\
\hline$T_{\mathrm{g}}\left[{ }^{\circ} \mathrm{C}\right]$ & -17.8 & -18.5 & -18.9 & -19.2 & -21.1 & -22.3 & -23.6 \\
\hline $\tan \delta_{[\text {max. }]}$ & 1.22 & 1.17 & 1.06 & 0.91 & 0.75 & 0.63 & 0.3 \\
\hline
\end{tabular}


Table 5. The data of stress-strain behaviors of NBR, $\mathrm{PU}-\mathrm{SiO}_{2}$ and NBR/(PU-SiO$\left.{ }_{2}\right)$ blends with different $\mathrm{PU}-\mathrm{SiO}_{2}$ loading

\begin{tabular}{|l|c|c|c|c|c|c|c|}
\hline \multirow{2}{*}{ Properties } & \multicolumn{7}{c|}{ PU-SiO content $[\mathbf{w t} \%]$} \\
\cline { 2 - 8 } & $\mathbf{0 ~ ( N B R )}$ & $\mathbf{1 0}$ & $\mathbf{2 0}$ & $\mathbf{3 0}$ & $\mathbf{4 0}$ & $\mathbf{5 0}$ & $\mathbf{1 0 0}\left(\mathbf{P U}-\mathbf{S i O}_{2}\right)$ \\
\hline $100 \%$ Modulus $[\mathrm{MPa}]$ & $1.3 \pm 0.1$ & $1.5 \pm 0.1$ & $1.7 \pm 0.1$ & $2.1 \pm 0.1$ & $2.8 \pm 0.1$ & $3.5 \pm 0.1$ & $5.6 \pm 0.1$ \\
\hline $300 \%$ Modulus $[\mathrm{MPa}]$ & - & $3.0 \pm 0.1$ & $3.6 \pm 0.2$ & $4.6 \pm 0.1$ & $6.1 \pm 0.1$ & $8.1 \pm 0.1$ & $13.1 \pm 0.2$ \\
\hline Tensile strength $[\mathrm{MPa}]$ & $1.9 \pm 0.4$ & $8.0 \pm 0.5$ & $14.0 \pm 0.5$ & $20.6 \pm 0.6$ & $23.5 \pm 0.5$ & $25.2 \pm 0.5$ & $26.0 \pm 0.5$ \\
\hline Elongation at break [\%] & $281 \pm 10$ & $481 \pm 13$ & $520 \pm 12$ & $535 \pm 15$ & $518 \pm 12$ & $530 \pm 12$ & $406 \pm 13$ \\
\hline Tear strength $[\mathrm{kN} / \mathrm{m}]$ & $8.2 \pm 1.0$ & $20.8 \pm 1.2$ & $25.8 \pm 1.3$ & $31.7 \pm 0.9$ & $40.2 \pm 1.1$ & $52.3 \pm 0.9$ & $58.4 \pm 1.0$ \\
\hline Shore A hardness & 52 & 53 & 55 & 63 & 65 & 72 & 81 \\
\hline
\end{tabular}

increases in the modulus, tensile strength, elongation at break, hardness and tear strength are achieved (Table 5). When the $\mathrm{PU}-\mathrm{SiO}_{2}$ content increases from 0 to $50 \mathrm{wt} \%$, the tensile strength and tear strength increase from $1.9 \mathrm{MPa}$ and $8.2 \mathrm{kN} / \mathrm{m}$ to $25.2 \mathrm{MPa}$ and $52.3 \mathrm{kN} / \mathrm{m}$, which are 1226 and $538 \%$ higher than those for NBR respectively. This demonstrates that the $\mathrm{PU}-\mathrm{SiO}_{2}$ hybrid network could significantly enhance the NBR vulcanizate. This is consistent with the above morphology results. The formation of quasi-IPN structures in the blends with

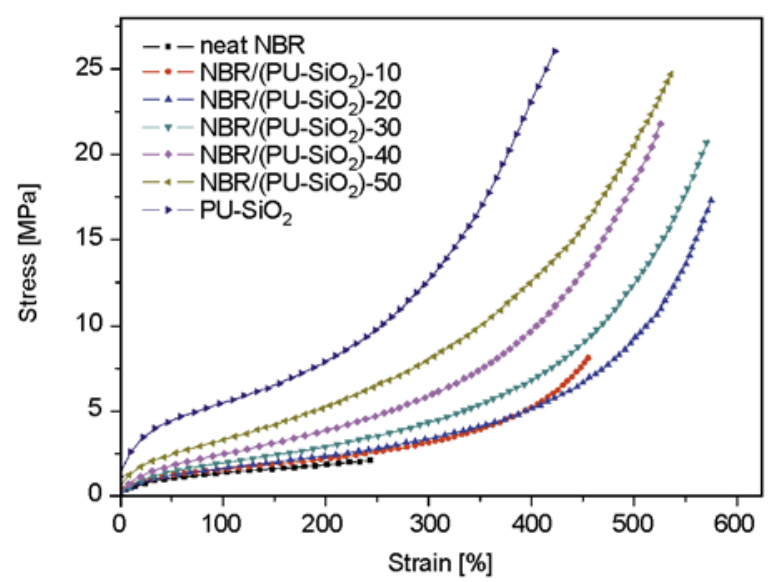

Figure 12. The stress-strain behaviors of NBR, $\mathrm{PU}-\mathrm{SiO}_{2}$ and $\mathrm{NBR} /\left(\mathrm{PU}-\mathrm{SiO}_{2}\right)$ blends with different PU$\mathrm{SiO}_{2}$ loading

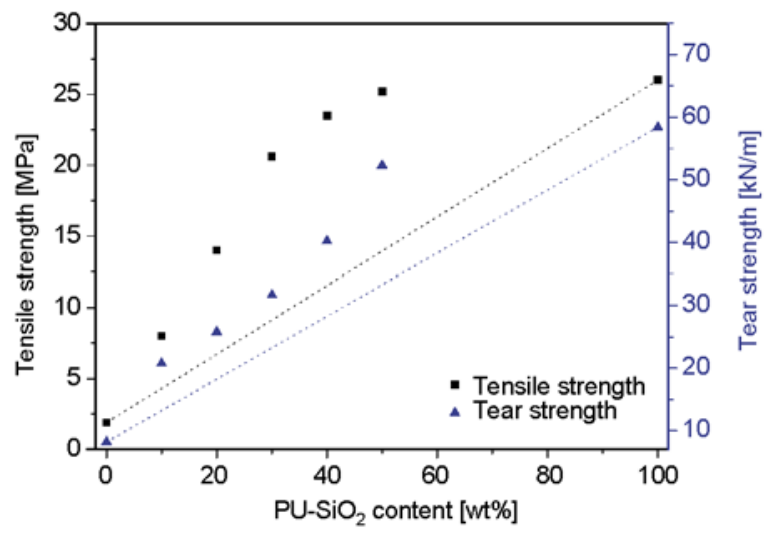

Figure 13. Dependence of tensile strength and tear strength of $\mathrm{NBR} /\left(\mathrm{PU}-\mathrm{SiO}_{2}\right)$ blends on the PU-SiO 2 content high $\mathrm{PU}-\mathrm{SiO}_{2}$ content are beneficial to the improvement of the mechanical properties $[30,31]$, as the mechanical properties of the systems reach maximum for the NBR/(PU-SiO $\left.)_{2}\right)$ blends. The tensile strength and tear strength as a function of weight fraction of $\mathrm{PU}-\mathrm{SiO}_{2}$ in blends are shown in Figure 13. As can be seen, the tensile strength and tear strength of the NBR/(PU-SiO $\left.{ }_{2}\right)$ blends show a positive deviation from linearity in all cases, which exhibits synergistic behavior. The improved mechanical properties and synergistic behavior are mainly caused by the good compatibility of NBR and PU$\mathrm{SiO}_{2}$ [32]. The elongation at break of the NBR/(PU$\mathrm{SiO}_{2}$ ) blends increases with the addition of PU$\mathrm{SiO}_{2}$ and exceeds those of the neat NBR and $\mathrm{PU}-\mathrm{SiO}_{2}$, which exhibits that the incorporation of $\mathrm{PU}-\mathrm{SiO}_{2}$ hybrid network does not deteriorate the elasticity of the NBR.

\subsubsection{Abrasion resistance and flex-fatigue life}

The Akron abrasion loss and flex-fatigue life of $\mathrm{NBR} /\left(\mathrm{PU}-\mathrm{SiO}_{2}\right)$ blends with different amounts of $\mathrm{PU}-\mathrm{SiO}_{2}$ are shown in Figure 14. The results reveal that the Akron abrasion loss of NBR/(PU-SiO $\left.{ }_{2}\right)$ blend is significantly decreased with increasing PU$\mathrm{SiO}_{2}$ content. When the $\mathrm{PU}-\mathrm{SiO}_{2}$ increases from 0 to

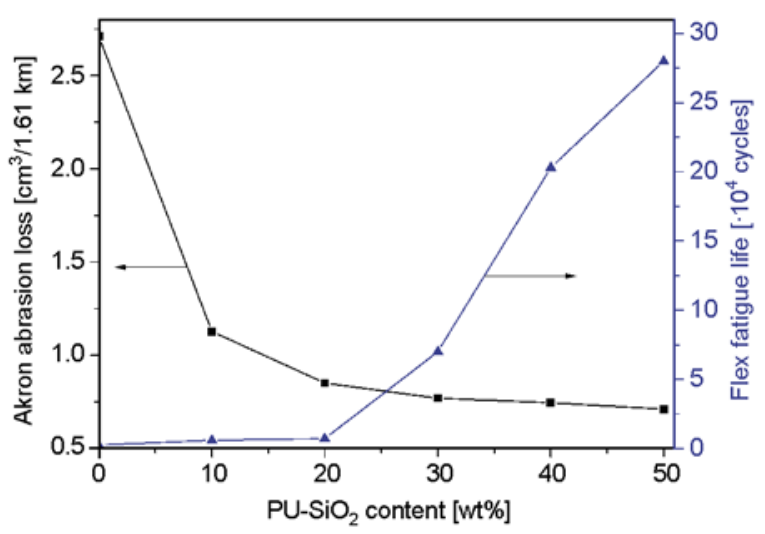

Figure 14. Effect of the amount of $\mathrm{PU}-\mathrm{SiO}_{2}$ on the Akron abrasion loss and flex-fatigue life of NBR/(PU$\mathrm{SiO}_{2}$ ) blends 
$50 \mathrm{wt} \%$, the value of Akron abrasion loss decreases from 2.71 to $0.71 \mathrm{~cm}^{3} / 1.61 \mathrm{~km}$, which is $73.8 \%$ lower than that for NBR. It can be seen that the PU$\mathrm{SiO}_{2}$ hybrid network can enhance the abrasion resistance of NBR greatly. It is well known that the abrasion resistance of PU is excellent [33]. The PU crosslinked by $\mathrm{SiO}_{2}$ preserves the outstanding abrasion resistance, the Akron abrasion loss of which is $0.45 \mathrm{~cm}^{3} / 1.61 \mathrm{~km}$. The abrasion resistance improvement of NBR after incorporation of $\mathrm{PU}-\mathrm{SiO}_{2}$ is mostly beacuase of the excellent abrasion resistance of the PU-SiO 2 .

From the curves of flex-fatigue life versus $\mathrm{PU}-\mathrm{SiO}_{2}$ content, it can be seen that when the PU-SiO ${ }_{2}$ content is less than $20 \mathrm{wt} \%$, the flex-fatigue life improvement is not great, while as the PU-SiO exceeds $20 \mathrm{wt} \%$, the flex-fatigue life is dramatically improved. Especially when the $\mathrm{PU}-\mathrm{SiO}_{2}$ amount increased from 20 to $30 \mathrm{wt} \%$, increasing the PU-SiO ${ }_{2}$ amount by only $10 \mathrm{wt} \%$ causes that the flex-fatigue life to increase nearly 10 times, from 7.2 thousand cycles to 70 thousand cycles. It is important to point out that the flex-fatigue life of neat NBR and $\mathrm{PU}-\mathrm{SiO}_{2}$ hybrid materials are 2.5 and 3.5 thousand cycles, respectively. However, the flex-fatigue life of NBR/(PU-SiO $\left.)_{2}\right)-50$ blend is 280 thousand cycles, which is more than 100 times that of neat NBR. It can be seen the flex-fatigue life of the individual components are relatively poor, while the flex-fatigue life of the resulting NBR/ $\left(\mathrm{PU}-\mathrm{SiO}_{2}\right)$ blends are improved significantly. The great improvement of flex-fatigue life of the NBR/ $\left(\mathrm{PU}-\mathrm{SiO}_{2}\right.$ ) blends may be explained in terms of the microstructures suggested in TEM analysis. With the increasing of PU-SiO ${ }_{2}$ content, the interpenetration and entanglement structures between NBR and $\mathrm{PU}-\mathrm{SiO}_{2}$ increase, these structures are beneficial to the improvement of flex-fatigue life.

\section{Conclusions}

Novel blends of NBR and in-situ produced PU$\mathrm{SiO}_{2}$ hybrid networks were prepared successfully by melt blending. The $\mathrm{PU}-\mathrm{SiO}_{2}$ hybrid networks were formed via the reaction of $\mathrm{NCO}$ groups of PU prepolymer and $\mathrm{OH}$ groups of $\mathrm{SiO}_{2}$ in the absence of an external crosslinking agent (i.e. alcohols and amines) during the curing process of NBR. The incorporation of $\mathrm{PU}-\mathrm{SiO}_{2}$ into NBR matrix led to higher curing rate, this is due to the mutual cure accelerating effects of NBR system and PU-SiO ${ }_{2}$ system. Transmission electronic microscopy (TEM) studies indicated that the interpenetration and entanglement structures between NBR and PU$\mathrm{SiO}_{2}$ increased with increasing $\mathrm{PU}-\mathrm{SiO}_{2}$ content and the quasi-interpenetrating polymer networks (quasi-IPN) structures were formed when the weight content of $\mathrm{PU}-\mathrm{SiO}_{2}$ was $50 \%$ in the NBR/(PU$\mathrm{SiO}_{2}$ ) systems. The DMA results showed that the compatibility between NBR and $\mathrm{PU}-\mathrm{SiO}_{2}$ was improved with $\mathrm{PU}-\mathrm{SiO}_{2}$ loading. The $\mathrm{PU}-\mathrm{SiO}_{2}$ hybrid network showed promising reinforceability towards the NBR compounds. The modulus, tensile strength, tear strength and hardness were found to be increased consistently with the content of PU$\mathrm{SiO}_{2}$. When the PU-SiO ${ }_{2}$ content was $50 \mathrm{wt} \%, 1226$ and $538 \%$ increases of tensile strength and tear strength of the neat NBR vulcanizate were achieved. The abrasion resistance and flex-fatigue life of NBR were improved significantly by the incorporation of $\mathrm{PU}-\mathrm{SiO}_{2}$. Further work will focus on the studies of reaction kinetics and phase separation kinetics of NBR and PU-SiO 2 components in the $\mathrm{NBR} /\left(\mathrm{PU}-\mathrm{SiO}_{2}\right)$ blends, and the factors affecting the reaction and phase separation kinetics. The purposes of these studies are to get finer structures in the NBR/(PU-SiO 2$)$ blends, which is important for the performance improvement of the blends.

\section{References}

[1] Paul D. R., Bucknall C. B.: Polymer blends: Formulation and performance. Wiley, New York (2000).

[2] Utracki L. A.: Polymer alloys and blends: Thermodynamics and rheology. Hanser, Munich (1989).

[3] Yasin K. A., Ansarifar A., Hameed S., Wang L.: A new method for crosslinking and reinforcing acrylonitrilebutadiene rubber using a silanized silica nanofiller. Polymer Advanced Technology, 22, 215-224 (2011). DOI: $10.1002 /$ pat.1518

[4] Wang X-P., Huang A-M., Jia D-M., Li Y-M.: From exfoliation to intercalation - Changes in morphology of HNBR/organoclay nanocomposites. European Polymer Journal, 44, 2784-2789 (2008).

DOI: $10.1016 /$ j.eurpolymj.2008.06.035

[5] Liu L., Jia D., Luo Y., Guo B.: Preparation, structure and properties of nitrile-butadiene rubber-organoclay nanocomposites by reactive mixing intercalation method. Journal of Applied Polymer Science, 100, 1905-1913 (2006).

DOI: 10.1002/app.22614 
[6] El-Nashar D. E., Ward A. A., Abd-El-Messieh S. L.: Physico-mechanical and dielectric properties of nitrile rubber filled with silica and mica. Kautschuk Gummi Kunststoffe, 62, 434-440 (2009).

[7] Samaržija-Jovanović S., Jovanović V., Marković G.: Thermal and vulcanization kinetic behaviour of acrylonitrile butadiene rubber reinforced by carbon black. Journal of Thermal Analysis and Calorimetry, 94, 797-803 (2008).

DOI: $10.1007 / \mathrm{s} 10973-007-8488-7$

[8] Bakare I. O., Pavithran C., Okieimen F. E., Pillai C. K. S.: Synthesis and characterization of rubber-seed-oilbased polyurethanes. Journal of Applied Polymer Science, 109, 3292-3301 (2008).

DOI: $10.1002 / a p p .28391$

[9] Deng J., Cao J., Li J., Tan H., Zhang Q., Fu Q.: Mechanical and surface properties of polyurethane/fluorinated multi-walled carbon nanotubes composites. Journal of Applied Polymer Science, 108, 2023-2028 (2008).

DOI: $10.1002 / a p p .27625$

[10] Kumar C. R., Karger-Kocsis J.: Curing and mechanical behavior of carboxylated NBR containing hygrothermally decomposed polyurethane. European Polymer Journal, 38, 2231-2237 (2002).

DOI: $10.1016 / \mathrm{S} 0014-3057(02) 00122-2$

[11] Im H. G., Ka K. R., Kim C. K.: Characteristics of polyurethane elastomer blends with poly(acrylonitrileco-butadiene) rubber as an encapsulant for underwater sonar devices. Industrial and Engineering Chemistry Research, 49, 7336-7342 (2010).

DOI: $10.1021 /$ ie100975n

[12] Kotal M., Srivastava S. K., Bhowmick A. K.: Thermoplastic polyurethane and nitrile butadiene rubber blends with layered double hydroxide nanocomposites by solution blending. Polymer International, 59, 2-10 (2010).

DOI: $10.1002 /$ pi.2686

[13] Tang T., Zhao H. Y., Chen H., Huang B. T.: The relationship of tensile strength with components for the binary multiphase blends (in Chinese). Polymer Materials Science and Engineering, 11, 1-5 (1995).

[14] Dimitrievski I., Susteric Z., Marinovic T.: Effect of PU-NBR interactions on blends' dynamic properties. in 'Proceedings $5^{\text {th }}$ European Rheology Conference Portoroz, Slovenia' vol V, 73-74 (1998).

[15] Karger-Kocsis J., Felhős D., Xu D.: Mechanical and tribological properties of rubber blends composed of HNBR and in situ produced polyurethane. Wear, 268, 464-472 (2010).

DOI: $10.1016 /$ j.wear.2009.08.037
[16] Šebenik U., Karger-Kocsis J., Krajnc M., Thomann R.: Dynamic mechanical properties and structure of in situ cured polyurethane/hydrogenated nitrile rubber compounds: Effect of carbon black type. Journal of Applied Polymer Science, 125, E41-E48 (2012).

DOI: $10.1002 / a p p .35626$

[17] Desai S., Thakore I. M., Brennan A., Devi S.: Polyurethane-nitrile rubber blends. Journal of Macromolecular Science: Pure and Applied Chemistry, 38, 711729 (2001).

DOI: $10.1081 / \mathrm{MA}-100103875$

[18] Madbouly S. A., Otaigbe J. U.: Recent advances in synthesis, characterization and rheological properties of polyurethanes and POSS/polyurethane nanocomposites dispersions and films. Progress in Polymer Science, 34, 1283-1332 (2009).

DOI: 10.1016/j.progpolymsci.2009.08.002

[19] Wirpsza Z.: Polyurethanes: Chemistry, technology and applications. Ellis Horwood Limited, New York (1993).

[20] Watts J. F., Wolstenholme J.: An introduction to surface analysis by XPS and AES. Wiley, Chichester (2003). DOI: $10.1002 / 0470867930$

[21] Moulder J. F., Stickle W. F., Sobol P. E., Bomben K. D.: Handbook of X ray photoelectron spectroscopy. Perkin-Elmer Corporation, Minnesota (1992).

[22] Mousa A., Karger-Kocsis J.: Application of hygrothermally decomposed polyurethane in rubber recipes Part 2 - Influence of hygrothermally decomposed polyester-urethane on cure characteristics and viscoelastic behaviour of styrene/butadiene rubber. Plastics, Rubber and Composites, 30, 309-313 (2001). DOI: $10.1179 / 146580101322913211$

[23] Karger-Kocsis J., Gremmels J., Mousa A., Ishiaku U. S., Ishak Z. A. M.: Application of hygrothermally decomposed polyurethane in rubber recipes Part 1: Natural rubber (NR) and nitrile rubber (NBR) stocks. Kautschuk Gummi Kunststoffe, 53, 528-533 (2000).

[24] Xu D., Karger-Kocsis J.: Unlubricated rolling and sliding wear against steel of carbon-black-reinforced and in situ cured polyurethane containing ethylene/propylene/diene rubber compounds. Journal of Applied Polymer Science, 115, 1651-1662 (2010).

DOI: $10.1002 / a p p .31156$

[25] Chen S., Wang Q., Pei X., Wang T.: Dynamic mechanical properties of castor oil-based polyurethane/epoxy graft interpenetrating polymer network composites. Journal of Applied Polymer Science, 118, 1144-1151 (2010).

DOI: 10.1002/app.32518

[26] Lu Y., Zhang L., Zhang X., Zhou Y.: Effects of secondary structure on miscibility and properties of semi-IPN from polyurethane and benzyl konjac glucomannan. Polymer, 44, 6689-6696 (2003).

DOI: $10.1016 / \mathrm{S} 0032-3861(03) 00594-9$ 
[27] Dean K., Cook W. D.: Effect of curing sequence on the photopolymerization and thermal curing kinetics of dimethacrylate/epoxy interpenetrating polymer networks. Macromolecules, 35, 7942-7954 (2002).

DOI: $10.1021 / \mathrm{ma} 020628 \mathrm{p}$

[28] Trakulsujaritchok T., Hourston D. J.: Damping characteristics and mechanical properties of silica filled PUR/PEMA simultaneous interpenetrating polymer networks. European Polymer Journal, 42, 2968-2976 (2006).

DOI: 10.1016/j.eurpolymj.2006.07.028

[29] Qin C-L., Cai W-M., Cai J., Tang D-Y., Zhang J-S., Qin M.: Damping properties and morphology of polyurethane/vinyl ester resin interpenetrating polymer network. Materials Chemistry and Physics, 85, 402-409 (2004).

DOI: 10.1016/j.matchemphys.2004.01.019

[30] John J., Suriyakala R., Thomas S., Mendez J. M., Pius A., Thomas S.: Morphology, mechanical and thermal properties of nano-structured full IPNs based on polyisoprene and PMMA. Journal of Materials Science, 45, 2892-2901 (2010).

DOI: $10.1007 / \mathrm{s} 10853-010-4280-3$
[31] Hsieh K. H., Han J. L., Yu C. T., Fu S. C.: Graft interpenetrating polymer networks of urethane-modified bismaleimide and epoxy (I): Mechanical behavior and morphology. Polymer, 42, 2491-2500 (2001).

DOI: 10.1016/S0032-3861(00)00641-8

[32] Karabanova L. V., Boiteux G., Seytre G., Stevenson I., Gain O., Hakme C., Lutsyk E. D., Svyatyna A.: Semiinterpenetrating polymer networks based on polyurethane and poly(2-hydroxyethyl methacrylate): Dielectric study of relaxation behavior. Journal of Non-Crystalline Solids, 355, 1453-1460 (2009). DOI: $10.1016 /$ j.jnoncrysol.2009.05.002

[33] Kannan M., Bhagawan S. S., Jose T., Thomas S., Joseph K.: Preparation and characterization of nanoclay-filled polyurethane/polypropylene blends. Polymer Engineering and Science, 50, 1878-1886 (2010). DOI: $10.1002 /$ pen. 21703 